\title{
Cross-reaction of antigen preparations from adult and larval stages of the parasite Setaria equina with sera from infected humans with Wuchereria bancrofti
}

M.M. Bahgat, ${ }^{7}$ A.H. Saad, ${ }^{2}$ G.A. El-Shahawi, ${ }^{3}$ A.M. Gad, ${ }^{4}$ R.M. Ramzy, ${ }^{5}$ A. Ruppel ${ }^{6}$ and M. Abdel-Latif ${ }^{3}$

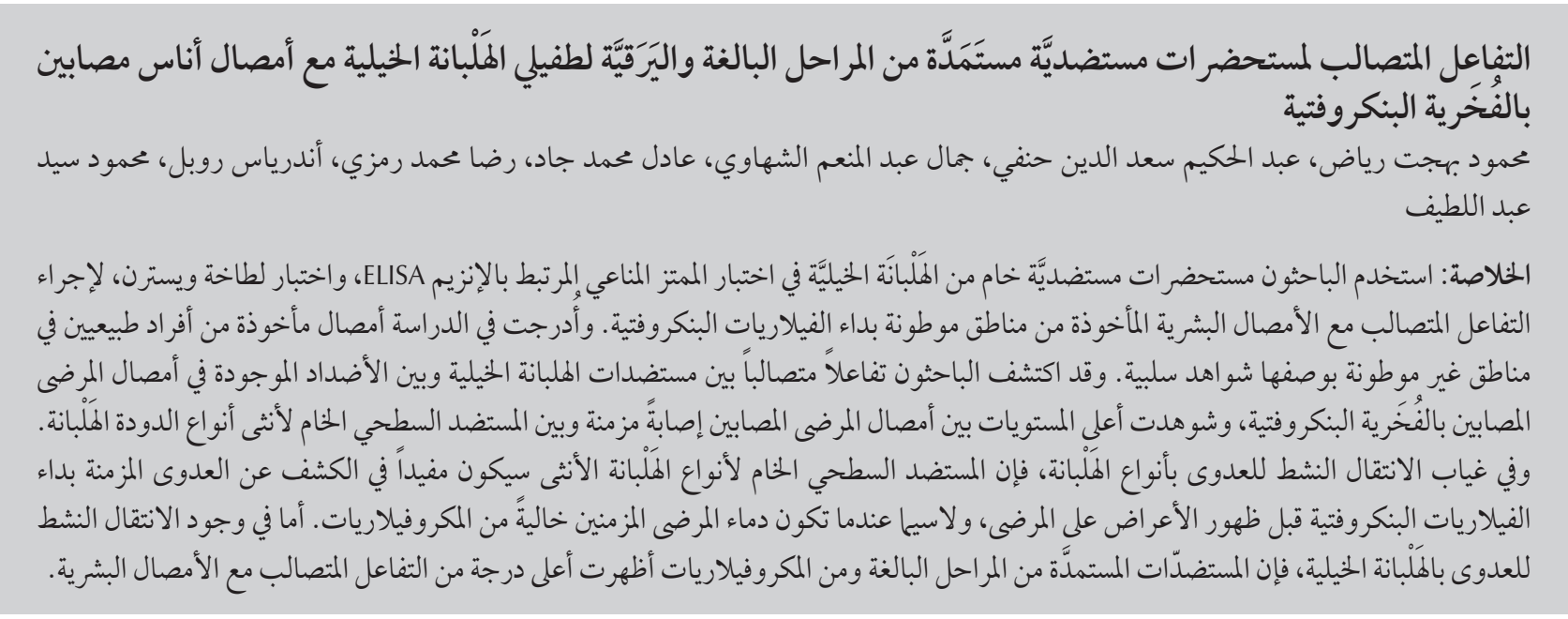

ABSTRACT Crude antigenic preparations from Setaria equina were used in ELISA and Western blotting to examine crossreaction with human sera from areas endemic for bancroftian filariasis. Sera from normal subjects from non-endemic areas were included as negative controls. Cross-reaction was found between S. equina antigens and antibodies in the sera of Wuchereria bancrofti-infected patients, with the highest levels observed between sera of chronic infected patients and Setaria spp. crude female worm surface antigen (CFSWA). In the absence of active transmission of Setaria spp. infection, CFWSA is useful to detect chronic $W$. bancrofti infection before patients become symptomatic, particularly when chronic patients are known to be amicrofilaraemic. In the presence of active $S$. equina infection, antigens from the adult and microfilaraemic stages showed the highest degree of cross-reaction with human sera.

Réaction croisée entre des préparations d'antigènes provenant du parasite Setaria equina aux stades larvaire et adulte et les sérums de personnes infestées par Wuchereria bancrofti

RÉSUMÉ Des préparations d'antigènes bruts de Setaria equina ont été utilisées dans le cadre des méthodes ELISA et transfert Western afin d'étudier la réaction croisée avec des sérums humains en provenance de zones endémiques pour la filariose de Bancroft. Des sérums prélevés chez des sujets normaux vivants dans des zones non endémiques ont été inclus en tant que témoins négatifs. Une réaction croisée a été observée entre les antigènes S. equina et les anticorps des sérums prélevés chez des patients infestés par Wuchereria bancrofti, les taux les plus élevés ayant été observés dans le cas de la réaction croisée entre les sérums des patients chroniquement infestés et l'antigène de surface brut de ver femelle Setaria spp. En l'absence de transmission active de l'infestation par Setaria spp., l'antigène de surface brut de ver femelle Setaria spp. est utile pour détecter une infestation chronique à $W$. bancrofti avant l'apparition des symptômes, notamment lorsqu'une amicrofilarémie a été diagnostiquée chez des patients chroniquement infestés. En présence d'une infestation active à $S$. equina, la plus forte réaction croisée a été observée entre les antigènes provenant des stades adultes et microfilarémiques et des sérums humains.

'Department of Therapeutic Chemistry and Infectious Diseases and Immunology Laboratory, Centre of Excellence for Advanced Sciences, National Research Centre, Dokki, Cairo, Egypt (Correspondence to M. Bahgat:mbahgatriad@yahoo.com).

${ }^{2}$ Department of Zoology, Faculty of Science, University of Cairo, Cairo, Egypt. ${ }^{3}$ Department of Zoology, Faculty of Science, University of Beni-Suef, Beni-Suef, Egypt. ${ }^{4}$ Department of Entomology, Ain Shams University, Cairo, Egypt. ${ }^{5}$ National Nutrition Institute, General Organization for Teaching Hospitals and Institutes, Cairo, Egypt. ${ }^{6}$ Department of Tropical Hygiene and Public Health, University of Heidelberg, Heidelberg, Germany.

Received: 08/12/09; accepted: 25/11/09 


\section{Introduction}

Adult Setaria equina is a filarial parasite commonly found floating free within the peritoneal cavity of equines in all parts of the world [1]. In most cases, S. equina are considered nonpathogenic in their natural hosts. However, serious pathogenic effects can occur when such a parasite is found in unusual habitats such as the ocular globe or central nervous system [2]. Worldwide, several surveys have revealed a high incidence of the parasite both in equines and in its vectors [3-6], where its morphology was previously described using both light and electron microscopes $[7,8]$.

Cross-reaction has previously reported been between the antigens of S. equina, S. cervi and S. digitata adult worms and sera from humans infected with Wuchereria bancrofti (roundworms), the parasites that cause lymphatic filariasis [9-12]. In addition, cross-reactivity of crude adult worms of the animal filarial parasites Dirofilaria immitis, Brugia pahangi $[13,14]$ and the larval stages of Dir. immitis [13] with antibodies in the sera of humans residing in endemic areas for human filariasis was found. In Egypt, antigens derived from Dipetalonema evansi, Litomosoides carinii and Dir. immitis were also found to be cross-reactive [15-20].

Many previous reports have documented the existence of zoonotic filarial infections, such as Dirofilaria spp [2125], Onchocerca spp [26], and Brugia spp $[27,28]$. Also, infections by both Dir. immitis and $W$. bancrofti were observed in both Aedes polynesiensis and Ae. samoanus mosquitoes in Samoa [29]. Thus, if the serodiagnostic methods used for detection of human filariasis are based on common antigens between animal and human filarial parasites, this may lead to false conclusions, e.g. predictions about a resurgence of human filariasis in a setting where animal filariasis is endemic. These cross-reactive antigens among human and animal filarial parasites need to be identified. The probability of S. equina transmission to humans, either by $W$. bancrofti vector species or by others, is not yet known.

The focus of previous studies was to identify antigens from available filarial parasites including those in animals in order to diagnose $W$. bancrofti infection $[11,30]$. However the possibility of human infection with those parasites and subsequent misdiagnosis has received little attention. In this study, we examined the extent of cross-reaction among antigens prepared from different stages of S. equina with well-characterized sera collected from human subjects infected with $W$. bancrofti.

\section{Methods}

\section{Collection of parasite stages}

Horses and donkeys $(n=367)$ of different ages and sexes with suspected filarial infections were examined after slaughtering from August 2004 to February 2008 in Beni-Suef governorate. Adult S. equina of both sexes were collected in peritoneal fluid, washed 3 times with cold phosphate buffered saline (PBS) containing $100 \mathrm{U} / \mathrm{mL}$ penicillin and $100 \mu \mathrm{g} / \mathrm{mL}$ streptomycin and frozen at $-85^{\circ} \mathrm{C}$. Microfilariae were collected in vitro, either on spontaneous release from female worms [31] or by mechanical disruption of worm uteri in Tyrode solution, followed by isolation of microfilariae using Percoll gradient centrifugation [32].

\section{Antigen preparation}

The following were prepared: soluble femaleand male S. equina antigens (SFWA and SMWA) [33], crude female worm surface antigen (CFSWA) [10] and female worm excretory-secretory antigen (FWESA) [31]. Microfilarial antigen (MFA) was prepared by homogenization in coating buffer for enzyme-linked immunosorbent assay (ELISA) [34] or electrophoresis sample buffer for Western blotting [35].

\section{Human sera}

Human blood samples were collected from areas endemic for $W$. bancrofti in Egypt: 19 samples were from amicrofilaraemic chronic patients who had apparent symptoms of lymphoedema and elephantiasis; 20 samples were from microfilaraemic individuals who had not developed any symptoms of the disease; 20 samples were from endemic normal subjects who were defined as individuals residing in an endemic setting but had never developed microfilaraemia or symptoms, although their sera may have parasite antigens or antiparasite antibodies; and 11 sera samples were collected from nonendemic normal individuals who had no history of the disease and had never been in an area endemic for bancroftian filariasis. Blood samples were centrifuged at $12000 \mathrm{~g}$, sera were collected, aliquoted and frozen at $-85^{\circ} \mathrm{C}$ until use.

\section{ELISA}

The assay was carried out in U-shaped polyvinyl microtitre plates (Alto) [36]. Briefly, plates were coated with SFWA, SMWA, CFWSA, FWESA or MFA antigens in coating buffer $(100 \mu \mathrm{L} /$ well; $3 \mathrm{~h}$ at room temperature) with the optimum antigen concentrations ( 0.2 , $0.1,0.5,0.03,0.11,0.05$ and $0.03 \mu \mathrm{g}$ protein/well respectively, based on results obtained from preliminary block titration experiments). Plates were washed and blocked $\left(1 \mathrm{~h}\right.$ at $\left.37^{\circ} \mathrm{C}\right)$. Individual human sera from chronic infected, microfilaraemic, endemic normal and nonendemic normal subjects were diluted and loaded to the plate wells in duplicates $(100 \mu \mathrm{L} /$ well $)$ and incubated for $2 \mathrm{~h}$ at $37^{\circ} \mathrm{C}$. Antibody binding was detected using diluted (1:20 000) peroxidase-conjugated goat antihuman IgG (Jackson Immuno Research Laboratories; Dianova). Visualization of the antigen-antibody reaction was 
detected using the substrate O-phenylenediamine (Sigma) and changes in optical density (OD) were recorded at $\lambda \max 490 \mathrm{~nm}$ using a multi-well plate reader (Sunrise, Tecan). Positive reactions were those with ODs above the respective cutoff values, which were determined by the mean $\operatorname{Ig} G$ reactivities in control sera against each antigen used plus 2 standard deviations.

\section{Electrophoresis and immunoblotting analysis}

Protein profiles of different antigenic preparationsfromS.equinawereanalysed by sodium dodecyl sulfate polyacrylamide gel electrophoresis (SDS-PAGE) [37] through $4 \%$ stacking and $12 \%$ resolving gels $(55 \times 85 \times 1 \mathrm{~mm})$ under reducing conditions. Low and high molecular weight markers ranging from 14.5 to $97 \mathrm{kDa}$ and 45 to $200 \mathrm{kDa}$ (BioRad Laboratories) were included on the same gels. Following electrophoresis, gels were Coomassie stained or electrophoretically transferred [38] from the gel to nitrocellulose sheets (BA85, pore size $0.45 \mu \mathrm{m}$; Schleicher and Schüll). Based on their reactivities in ELISA, the sera from chronic, microfilaraemic and endemic normal subjects were classified into highly, moderately and weakly reactive groups. Pools for such groups as well as that of nonendemic normal sera were used at dilution 1:150 in PBS-0.3\% Tween. Incubation and washing conditions have been described previously [39]. The immunodetection was carried out with peroxidase-conjugated goat antibodies to human $\operatorname{IgG}(1: 10000$; Bio-Rad Laboratories). Visualization of antigen-antibody binding on the nitrocellulose strips was carried out by developing the strips with the substrate 3 , 3-diaminobenzidine substrate (Sigma).

\section{Statistical analysis}

The data were analysed using Student $t$ test and Pearson correlation coefficient. All statistical analyses were carried out using the Practistat statistical program (Ashcroft-Pereira).
Results

\section{Electrophoresis of crude parasite antigen}

The Coomassie staining profile of the SFWA, SMWA, CFWSA, FWESA and MFA antigens resolved by SDS-PAGE are presented in Figure 1. The results showed clear differences in protein patterns among these antigens. FWESA did not show any stained bands.

\section{IgG detection by ELISA}

The results showed that the highest prevalences of IgG antibodies against all antigen preparations were recorded among amicrofilaraemic chronic infected patients (Table 1). SFWA showed generally higher sensitivity in detecting IgG than SMWA. For both antigenic preparations, the $\operatorname{IgG}$ positive reactions were in the order: chronic > microfilaraemic > endemic normal subjects. All sera of chronic infected patients were uniformly IgG positive to CFWSA, while sera of both microfilaraemic and endemic normal subjects showed less reactivity. None of the microfilaraemic or endemic normal sera were $\operatorname{Ig} G$ posi- tive for MFA, while few of the sera from chronic patients were IgG-positive.

\section{Detection of immunonogenic peptides by Western blotting}

Sera from chronic infected patients that were classified as highly reactive in the ELISA (OD $\geq 0.38$ ) strongly recognized immunogenic bands at $93.3 \mathrm{kDa}$ in SFWA, $100.5 \mathrm{kDa}$ in FWESA and $24 \mathrm{kDa}$ in MFA (Figure 2). Moderately reactive sera from chronic patients (OD $\geq 0.26$ ) recognized an immunogenic band at $27.8 \mathrm{kDa}$ in CFSWA. Weakly reactive sera from chronic patients $(\mathrm{OD} \geq 0.15)$ recognized immunogenic bands at 17 and $60 \mathrm{kDa}$ in SFWA and MFA respectively. All chronic patients' sera recognized immunogenic bands at $33.6 \mathrm{kDa}$ in SFWA and $200 \mathrm{kDa}$ in both CFSWA and FWESA.

Highly reactive sera from microfilaraemic asymptomatic subjects (OD $\geq 0.34$ ) strongly recognized immunogenic bands at $33.6 \mathrm{kDa}$ in SFWA and $66.2 \mathrm{kDa}$ in SMWA. Weakly reactive $(\mathrm{OD} \geq 0.16)$ microfilaraemic sera recognized immunogenic bands at 81.0 $\mathrm{kDa}$ in SFWA. All sera from both the chronic patients and microfilaraemic

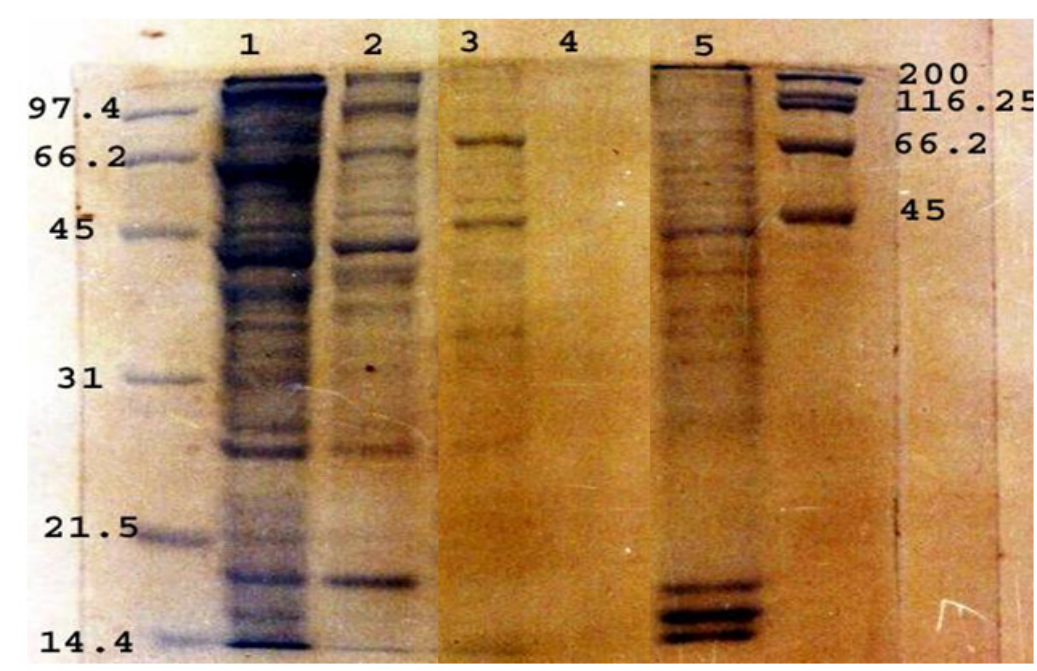

Figure 1 Coomassie staining profile of SDS-12.5\% PAGE resolved soluble female worm antigen (lane 1), soluble male worm antigen (lane 2), crude female worm surface antigen (lane 3), female worm extracted-secretory antigen (lane 4) and microfilarial antigen (lane 5) under reducing conditions in comparison to low (left) and high (right) molecular weight markers 
subjects recognized antigenic bands at $200 \mathrm{kDa}$ in both CFWSA and FWESA, while only the highly reactive sera from endemic normal subjects recognized the same band in CFWSA.

The highly reactive endemic normal sera $(O D \geq 0.44)$ recognized a common immunogenic band at $81.0 \mathrm{kDa}$ in SFWA and SMWA and also 33.6, 45.0 and 66.2 $\mathrm{kDa}$ in SMWA (Figure 2). Only highly and moderately reactive endemic normal patients' sera $(O D \geq 0.23)$ recognized a $200.0 \mathrm{kDa}$ band in CFWSA, while both highly reactive microfilaraemic subjects' and endemic normal patients' sera shared recognition of the $81 \mathrm{kDa}$ immunogenic band in SMWA.

\section{Discussion}

In this study, we attempted to determine the extent of cross-reactivity of antigens derived from animal filarial parasites such as $S$. equina with sera from humans infected with $W$. bancrofti. This could help us to predict the influence of human infection with the parasite infective stages on the sensitivities of $W$. bancrofti diagnostic tests [40].

Comparing the efficiency of different tests in the serodiagnosis of bancroftian filariasis has shown that the ELISA method is simple and sensitive [41]. In the present study, sera from symptomatic chronic patients and asymptomatic microfilaraemic subjects did not show any IgM reactivity against the prepared crude antigens in comparison with the sera from normal subjects who had never been in an endemic area (data not shown). However, the reactivity of $\operatorname{IgG}$ in the same sera was obvious when compared with the sera from nonendemic normal subjects. It is noteworthy that IgM was previously considered as having a higher reactivity over $\operatorname{Ig} G$ for detection of active filarial infection using Dir. immitis soluble antigen [19]. Accordingly, the present study focused on monitoring $\operatorname{IgG}$ reactivity in human sera using both ELISA and Western blotting. In ELISA, the observed higher positive $\operatorname{IgG}$ reactivity against all the antigenic preparations for human sera from chronic patients in comparison with other human sera might be attributed to worm death in chronic patients, which could expose these patients to more antigenic determinants released from dead worms. This hypothesis was previously used to explain the higher humoral reactivity of symptomatic patients to the detergent-extracted antigen rather than the soluble one [42]. Generally, the presence of microfilariae in blood is immunosuppressive for antibody production $[43,44]$.

We observed a higher IgG positivity among microfilaraemic patients to the crude female (CFWSA) than male S. equina worm antigens (CMWSA), which could be explained by exposure of such patients to cross-reactive $W$. bancrofti female epitopes rather than male ones. The IgG reactivity in the sera of some asymptomatic nonmicrofilaraemic human individuals (the endemic normals), was positive to all antigenic preparations from $S$. equina adult worms. This may be due to the presence of cryptic adult worm infections or ultra-low levels of microfilaraemia in those individuals that did not allow detection of infection by conventional parasitological examination $[45,46]$.

It was not surprising that all sera from chronic patients were crossreactive with $S$. equina CFWSA, as was previously reported in a study in India focusing on S. digitata [10]. The cross-reaction of IgG antibodies in $W$. bancrofti-infected human sera with Dir. immitis and Dip. evansi sonicated microfilarial antigens has been previously reported $[15,47]$. In our study, only

\begin{tabular}{|c|c|c|c|c|c|c|c|}
\hline \multirow[t]{3}{*}{ Antigen preparation } & \multirow{3}{*}{$\begin{array}{l}\text { Cut-off } \\
\text { value }\end{array}$} & \multicolumn{6}{|c|}{ Human sera from: } \\
\hline & & \multicolumn{2}{|c|}{$\begin{array}{l}\text { Amicrofilaraemic chronic } \\
\text { patients } \\
(n=19)\end{array}$} & \multicolumn{2}{|c|}{$\begin{array}{l}\text { Microfilaraemic patients } \\
\qquad(n=20)\end{array}$} & \multicolumn{2}{|c|}{$\begin{array}{l}\text { Endemic normal subjects } \\
\qquad(n=20)\end{array}$} \\
\hline & & $\begin{array}{l}\operatorname{lgG} \\
\text { prevalence } \\
(\%)\end{array}$ & $P$-value ${ }^{a}$ & $\begin{array}{l}\operatorname{lgG} \\
\text { prevalence } \\
(\%)\end{array}$ & $P$-value ${ }^{a}$ & $\begin{array}{c}\lg G \\
\text { prevalence } \\
(\%)\end{array}$ & $P$-value ${ }^{a}$ \\
\hline $\begin{array}{l}\text { Soluble } S \text {. equina female } \\
\text { antigen }\end{array}$ & 0.29 & 73.7 & $<0.001$ & 55.0 & $<0.01$ & 15.0 & NS \\
\hline $\begin{array}{l}\text { Soluble } S \text {. equina male } \\
\text { antigen }\end{array}$ & 0.42 & 47.4 & $<0.020$ & 20.0 & NS & 5.0 & NS \\
\hline $\begin{array}{l}\text { Crude female worm surface } \\
\text { antigen }\end{array}$ & 0.14 & 100.0 & $<0.001$ & 60.0 & $<0.01$ & 40.0 & $<0.05$ \\
\hline $\begin{array}{l}\text { Female worm excretory- } \\
\text { secretory antigen }\end{array}$ & 0.23 & 36.8 & NS & 10.0 & NS & 50.0 & NS \\
\hline Microfilarial antigen & 0.64 & 31.5 & $<0.020$ & 0.0 & $<0.01$ & 0.0 & $<0.001$ \\
\hline
\end{tabular}

${ }^{a}$ Student $t$-test.

$N S=$ not significant . 

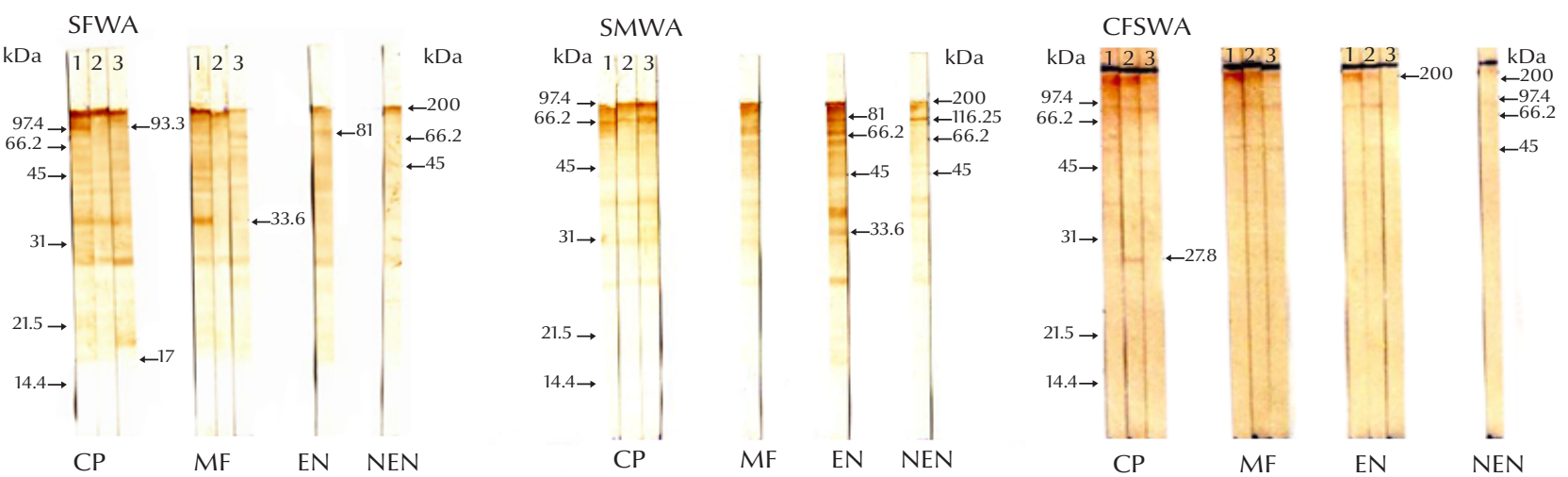

FWESA
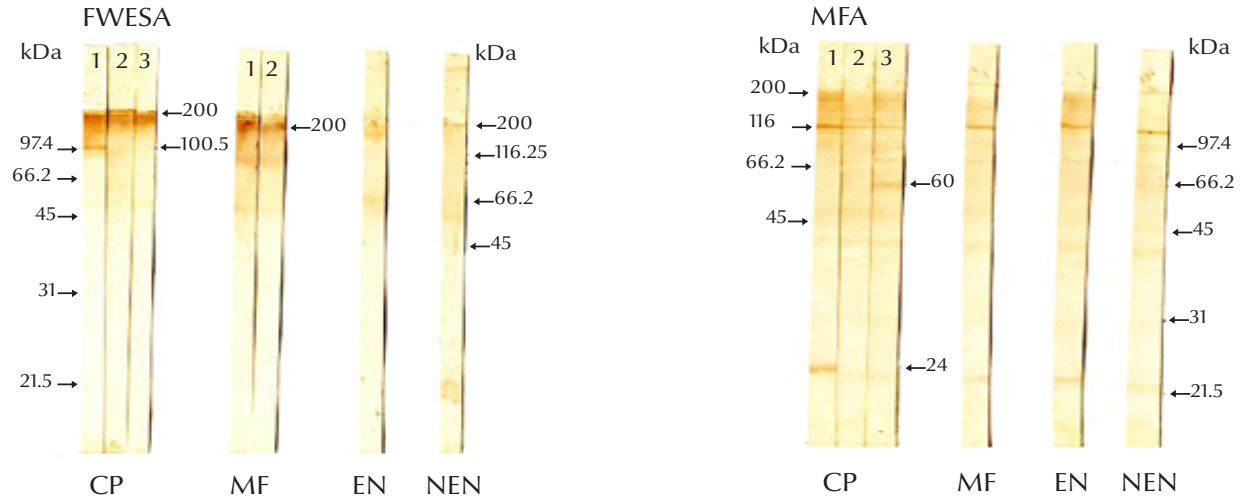

Figure 2 Western blots showing immunogenic bands of prepared antigens recognized by high (lane 1), moderate (lane 2) and weak (lane 3$)$ IgG reactivity in human sera $(C P=$ chronic amicrofilaraemic patients, $M F A=$ microfilaraemic asymptomatic subjects, $\mathrm{EN}=$ normal subjects from endemic area, NEN = normal controls from nonendemic area). Both low (left) and high (right) molecular weight markers were included

$31.5 \%$ of chronic patients' sera were IgG positive against the sonicated microfilarial antigen of S. equina (MFA), while all microfilaraemic and endemic normal sera were uniformly negative. Whether this cross-reactivity between MFA and chronic patients' sera is related to cross-reactive antigens from dead worms or amicrofilaremia remains unknown. The possibility that this is related to the immune clearance of blood microfilariae (amicrofilaraemia) is not inconsistent with previous immunological studies showing that many patients with chronic lymphatic obstruction are amicrofilaraemic because they are no longer infected with filarial parasites $[48,49]$. In addition, endemic normal individuals who are amicrofilaraemic were $\operatorname{IgG}$ negative. It is noteworthy that microscopic examination after sonication revealed that the outer sheath of the majority of microfilariae was completely shed, while few microfilariae were cut (data not shown). The microfilariae sheath might represent a source of cross-reactive carbohydrate antigens with worms that result in reactivity of microfilariae antigen with $\mathrm{IgG}$ in some chronic patients' sera [50]. Recently, anti-sheath antibodies were found to play a role in clearance of microfilaraemia and circulating filarial antigen in $W$. bancrofti infections [51]. The crossreactivity of some endemic normal sera with the antigens derived from adult worms rather than with the microfilarial antigen supports our interpretation that those individuals may have had adult worm cryptic or unisexual infections $[45,46]$.

It was previously suggested that the excretory-secretory antigens of Setaria spp. are formed in the uterus during embryonic development and released during hatching [52]. Using FWESA as the antigen in ELISA, IgG reactivity was higher among sera from chronic patients than microfilaraemic individuals. The presence of free antigens released by the parasite as well as antigen-antibody complexes in the host's circulation system suggests that the antibody titre did not reach a level to completely neutralize these antigens [53]. This might allow us to conclude that lower IgG reactivity in microfilaraemic sera may be related to the existence of cross-reactive antigens in the form of immune complexes with most of IgG antibodies, while immune clearance of those antigens from the sera of chronic patients results in higher $\operatorname{IgG}$ reactivity $[48,54]$.

Immunoblotting has been used previously for analysing the antigenic proteins of filarial as well as other 
parasites and its superiority over other immunochemical techniques has been discussed [55-58]. Using this technique, the antigens that are crossreactive with different human sera could have been identified by their molecular weights. In our study, a common recognition of a protein band at $81 \mathrm{kDa}$ in the SFWA and SMWA by sera from both microfilaraemic and endemic normal individuals may be due to the cryptic infections present in some endemic normal individuals. Similarly, a common recognition of a protein band at $33.6 \mathrm{kDa}$ in SFWA in chronic patients' and microfilaraemic sera may be a consequence of a longlasting antibody response present in chronic patients' sera to antigen released from the female adult worm during its life. Positive IgG reactivity in chronic patients (100\%) against the CFWSA of S. equina by ELISA corresponded to recognition of a $27.8 \mathrm{kDa}$ band by chronic patients' sera. The controversy between the results of a previous study [10] and ours using infected human sera against CSFWA in immunoblotting may be due to either the different source of collected human sera or species-specific reactions. Recognition of 2 protein bands at 24 and $60 \mathrm{kDa}$ in MFA by both highly and weakly IgG reactive chronic patients' sera respectively could be associated with amicrofilaraemia. Those antigens can be further evaluated as protective antigens against microfilaraemia in animal models. A previous study indicated that IgG antibodies from mice immunized with an extract of B. malayi microfilariae could identify antigens at 25 and $60 \mathrm{kDa}$ [59]. The researchers further demonstrated that antibody titres of amicrofilaraemic human sera to $25 \mathrm{kDa}$ were higher than those of microfilaraemic ones.

A common recognition of $200 \mathrm{kDa}$ in FWESA by microfilaraemic and chronic patients' sera identifies cross-reactive epitope(s) between S. equina and $W$. bancrofti that can lead to misdiagnosis using the immunochromatographic card test. The same molecular weight was identified in W. bancrofti patient sera using rabbit polyclonal antibodies raised against excretory-secretory antigen of Dir. immitis adult worms [48]. The immune recognition of this molecular weight antigen in both S. equina CSFWA and FWESA by $W$. bancrofti-infected human sera was in concordance with the recognition of the same molecular weight antigen in excretory-secretory and surface preparations from B. malayi female worm by homologous infected human sera [60]. Recently, the same molecular weight glycoprotein was also identified in excretory-secretory preparations of $S$. digitata, suggesting that it may secreted through the surface pores of male and female adult worms [61].
In conclusion, our study demonstrated cross-reaction between S. equina antigens and antibodies in the sera of $W$. bancrofti-infected patients, with the highest levels observed between the chronic patients' sera and Setaria spp. CFWSA. In the absence of active transmission of Setaria spp. infection, such CFWSA can be useful to detect chronic $W$. bancrofti infection before patients become symptomatic, particularly when chronic patients are known to be amicrofilaraemic. The results suggest that in the presence of active S. equina infection it is important to avoid using antigens from both the adult and microfilaraemic stages as these showed the highest degree of cross-reaction with human sera, and that improved diagnostic tests should be developed for bancroftian filariasis. The capacity of the mosquitoes present in the Egyptian habitats to transmit Setaria spp. or any other animal filarial parasites that might cross-react with $W$. bancrofti has to be addressed.

\section{Acknowledgements}

We are grateful to the General Department of Malaria, Filariasis and Leishmaniasis Control at the Ministry of Health and Population for their cooperation in collecting the sera from chronic patients.

\section{References}

1. Coleman SU, Klei TR, French DD. Prevalence of Setaria equina (Nematode: Onchocercidae) in southeastern Louisiana horses. Journal of Parasitology, 1985, 71:512-513.

2. Hillyer L, Coles G, Randle R. Setaria equina in the UK. Veterinary Record, 2001, 149:464.

3. LeBrun RA, Dziem GM. Natural incidence of Setaria equina (Nematoda: Filarioidea) from Aedes canadensis (Diptera: Culicidae) in North America. Journal of Medical Entomology, 1984, 21:472-473.

4. Oge $\mathrm{S}$ et al. Setaria equina infection of Turkish equines: estimates of prevalence based on necropsy and the detection of microfilaraemia. Annals of Tropical Medicine and Parasitology, 2003, 97:403-409.

5. Hornok $\mathrm{S}$ et al. Prevalence of Setaria equina microfilaraemia in horses in Hungary. Veterinary Research, 2007, 161:814-816.
6. Marzok MA, Desouky AR. Ocular infection of donkeys (Equus asinus) with Setaria equina. Tropical Animal Health and Production, 2009, 41:859-863.

7. Shoho C, Uni S. Scanning electron microscopy (SEM) of some Setaria species (Filarioidea, Nematoda). Zeitschrift fur Parasitenkunde (Berlin, Germany), 1977, 53:93-104.

8. Li ZX, Yu LR. Morphological studies on the larval stages of three species of Setaria and Dirofilaria repens. Southeast Asian Journal of Tropical Medicine and Public Health, 1990, 21:95-102.

9. Camargo $\mathrm{M}$ et al. [Heterologous antigen in the immunological diagnosis of wucheriasis: Setaria equina extract used in the immunoenzymatic reaction-ELISA ] Antígeno heterólogo no diagnóstico imunológico da wuchereriose: extrato de Setaria equina utilizado na reação imunoenzimática-ELISA. Memorias do Instituto Oswaldo Cruz, 1982, 77:385-388. 
10. Theodore JG, Kaliraj P. Isolation, purification and characterization of surface antigens of the bovine filarial parasite Setaria digitata for the immunodiagnosis of bancroftian filariasis. Journal of Helminthology, 1990, 64:105-114.

11. Kaushal NA et al. Isolation of an antigen fraction from Setaria cervi adults having potential for immunodiagnosis of human filariasis. Immunological Investigations, 2009, 38:749-761.

12. Rathaur S et al. Setaria cervi dual specific phosphatase: characterization and its effect on eosinophil degranulation. Parasitology, 2009, 136:895-904.

13. Desowitz RS, Una SR. The detection of antibodies in human and animal filariases by counterimmunoelectrophoresis with Dirofilaria immitis antigens. Journal of Helminthology, 1976, 50:53-57.

14. Maizels RM et al. Specificity of surface molecules of adult Brugia parasites: cross-reactivity with antibody from Wuchereria, Onchocerca and other human filarial infections. Tropical Medicine and Parasitology, 1985, 36:233-237.

15. Rifaat MA et al. Preliminary evaluation of Dipetalonema evansi antigen in diagnosis of filariasis in Egypt by immunofluorescence antibody test. Journal of the Egyptian Society of Parasitology, 1982, 12:319-325.

16. El-Ganayani GA, el-Shazely AM, Abdel-Magied SA. Evaluation of ELISA and IHAT in immunodiagnosis of bancroftian filariasis using delipidized L. carinii antigen. Journal of the Egyptian Society of Parasitology, 1988, 18:111-117.

17. El-Ganayni GA et al. Diagnosis of bancroftian filariasis by detection of circulating antigens by counterimmunoelectrophoresis. Journal of the Egyptian Society of Parasitology, 1988, 18:503-507.

18. El-Ganayni GA. Evaluation of two different antigens in immunodiagnosis of bancroftian filariasis using ELISA and IHAT. Journa of the Egyptian Society of Parasitology, 1992, 22:107-113.

19. Ata $\mathrm{AH}$ et al. Antifilarial IgM versus IgG antibody determination in the diagnosis of Wuchereria bancrofti infection in Egyptians. Journal of the Egyptian Society of Parasitology, 1993, 23:277-288.

20. El Serougi AO et al. Evaluation of the IgG4 in Egyptian bancroftian filariasis. Journal of the Egyptian Society of Parasitology, 2000, 30:59-67.

21. Vakalis NC, Himonas CA. Human and canine dirofilariasis in Greece. Parassitologia, 1997, 39:389-391.

22. Petrocheilou $\mathrm{V}$ et al. Microfilaremia from a Dirofilaria-like parasite in Greece. Case report. Acta Pathologica, Microbiologica et Immunologica Scandinavica, 1998, 106:315-318.

23. Walther M, Muller R. Diagnosis of human filariases (except onchocerciasis). Advances in Parasitology, 2003, 53:149-193.

24. Sabu L, Devada K, Subramanian H. Dirofilariosis in dogs and humans in Kerala. Indian Journal of Medical Research, 2005, 121:691-693.

25. Kokta V. Zoonotic deep cutaneous filariasis-three pediatric cases from Québec, Canada. Pediatric Dermatology, 2008, 25:230-232.

26. Ishii $Y$ et al. Seasonal and diurnal biting activities and zoonotic filarial infections of two Simulium species (Diptera: Simuliidae) in northern Thailand. Parasite (Paris, France), 2008, 15:121-129.

27. Eberhard ML et al. Zoonotic Brugia infection in western Michigan. American Journal of Surgical Pathology, 1993, 17:10581061.

28. Elenitoba-Johnson KS et al. Zoonotic Brugian lymphadenitis. An unusual case with florid monocytoid B-cell proliferation. American Journal of Clinical Pathology, 1996, 105:384-387.

29. Chambers EW et al. Xenomonitoring of Wuchereria bancrofti and Dirofilaria immitis infections in mosquitoes from American Samoa: trapping considerations and a compari- son of polymerase chain reaction assays with dissection. American Journal of Tropical Medicine and Hygiene, 2009, 80:774-781.

30. Bal MS et al. Transplacental transfer of filarial antigens from Wuchereria bancrofti-infected mothers to their offspring. Parasitology, 2009, 23:1-5.

31. Thilagavathy AH, Prabha B, Raj RK. Excretory secretory antigens of filarial parasite Setaria digitata. Indian Journal of Experimental Biology, 1990, 28:291-292.

32. Medina-De la Garza CE, Brattig NW, Tischendorf FW. Rapid method for the purification of viable microfilariae from nodules of Onchocerca volvulus by Percoll gradient centrifugation. Tropical Medicine and Parasitology, 1987, 38:53-54.

33. Michaud LA, Lammie PJ. Regulation of jird lymphocyte responsiveness to fractionated antigens of Brugia pahangi. Tropical Medicine and Parasitology, 1988, 39:317-321.

34. Van Hoegaerden M, Akué JP. Lack of evidence for transplacental transfer of microfilarial antigens in filariasis due to Loa loa and Mansonella perstans. Tropical Medicine and Parasitology, 1986, 37:121-123.

35. Tamashiro WK et al. Dirofilaria immitis: studies on anti-microfilarial immunity in Lewis rats. American Journal of Tropical Medicine and Hygiene, 1989, 40:368-376.

36. Engvall E, Perlmann P. Enzyme-linked immunosorbent assay (ELISA). Quantitative assay of immunoglobulin G. Immunochemistry, 1971, 8:871-874.

37. Laemmli UK. Cleavage of structural proteins during the assembly of the head of bacteriophage T4. Nature, 1970, 227:680685

38. Towbin H, Staehelin T, Gordon J. Electrophoretic transfer of proteins from polyacrylamide gels to nitrocellulose sheets: procedure and some applications. Proceedings of the $\mathrm{Na}$ tional Academy of Sciences of the United States of America, 1979, 76:4350-4354.

39. Ruppel A, Diesfeld HJ, Rother U. Immunoblot analysis of Schistosoma mansoni antigens with sera of schistosomiasis patients: diagnostic potential of an adult schistosome polypeptide. Clinical and Experimental Immunology, 1985, 62:499-506.

40. Orihel TC, Eberhard ML. Zoonotic filariasis. Clinical Microbiology Reviews, 1998, 11:366-381.

41. Kaliraj P, Ghirnikar SN, Harinath BC. Immunodiagnosis of bancroftian filariasis: comparative efficiency of the indirect hemagglutination test, indirect fluorescent antibody test, and enzyme-linked immunosorbent assay done with Wuchereria bancrofti microfilarial antigens. American Journal of Tropical Medicine and Hygiene, 1981, 30:982-987.

42. Lammie PJ, Eberhard ML, Lowrie RC Jr. Differential humoral and cellular immunoreactivity to saline- and detergent-extracted filarial antigens. Transactions of the Royal Society of Tropical Medicine and Hygiene, 1990, 84:407-410.

43. Grove DI. Immunity in filariasis: a review. Papua and New Guinea Medical Journal, 1978, 21:32-42.

44. Lammie PJ et al. Alterations in filarial antigen-specific immunologic reactivity following treatment with ivermectin and diethylcarbamazine. American Journal of Tropical Medicine and Hygiene, 1992, 46:292-295.

45. Dreyer G et al. Amicrofilaraemic carriers of adult Wuchereria bancrofti. Transactions of the Royal Society of Tropical Medicine and Hygiene, 1996, 90:288-289.

46. Simonsen PE, Meyrowitsch DW. Bancroftian filariasis in Tanzania: specific antibody responses in relation to long-term observations on microfilaremia. American Journal of Tropical Medicine and Hygiene, 1998, 59:667-672.

47. Kaliraj P, Ghirnikar SN, Harinath BC. Indirect fluorescent antibody technique using sonicated Wuchereria bancrofti mi- 
crofilaria for immunodiagnosis of Bancroftian filariasis. Indian Journal of Experimental Biology, 1979, 17:332-335.

48. Weil GJ et al. A monoclonal antibody-based enzyme immunoassay for detecting parasite antigenemia in bancroftian filariasis. Journal of Infectious Diseases, 1987, 156:350-355.

49. Ramzy RM et al. Evaluation of a monoclonal-antibody based antigen assay for diagnosis of Wuchereria bancrofti infection in Egypt. American Journal of Tropical Medicine and Hygiene, 1991, 44:691-695.

50. Ravindran B et al. Antibodies to microfilarial sheath in bancroftian filariasis-prevalence and characterization. Annals of Tropical Medicine and Parasitology, 1990, 84:607-613.

51. Simonsen PE et al. Immunoepidemiology of Wuchereria bancrofti infection in two East African communities: antibodies to the microfilarial sheath and their role in regulating host microfilaraemia. Acta Tropica, 2008, 106:200-206.

52. Decruse SW, Kaleysaraj R. Excretory secretory material from different sites of female reproductive tissue of filarial parasite Setaria digitata. Indian Journal of Experimental Biology, 1988 , 26:781-783.

53. Sugunan VS, Raj RK. Excretory/secretory antigens from a bovine filarial parasite cross react with human antifilarial antibodies. Indian Journal of Experimental Biology, 1990, 28:1124-1127.

54. Dasgupta A, Bala S, Dutta SN. Lymphatic filariasis in man: demonstration of circulating antigens in Wuchereria bancrofti infection. Parasite Immunology, 1984, 6:341-348.
55. Weiss $\mathrm{N}$ et al. Detection of IgE-binding Onchocerca volvulus antigens after electrophoretic transfer and immuno-enzyme reaction. Acta Tropica, 1982, 39:373-377.

56. Lucius $\mathrm{R}$ et al. Identification of immunogenic proteins of Dipetalonema viteae (Filarioidea) by the "Western Blotting" technique. Tropical Medicine and Parasitology, 1983, 34:133-136.

57. Lobos E, Weiss N. Immunochemical comparison between worm extracts of Onchocerca volvulus from savanna and rain forest. Parasite Immunology, 1985, 7:333-347.

58. Hussain R, Kaushal NA, Ottesen EA. Comparison of immunoblot and immunoprecipitation methods for analyzing cross-reactive antibodies to filarial antigens. Journal of Immunological Methods, 1985, 84:291-301.

59. Kazura JW, Cicirello H, Forsyth K. Differential recognition of a protective filarial antigen by antibodies from humans with bancroftian filariasis. Journal of Clinical Investigation, 1986, 77:1985-1992.

60. Kwan-Lim GE et al. Secreted antigens of filarial nematodes: a survey and characterization of in vitro excreted/secreted products of adult Brugia malayi. Parasite Immunology, 1989, 11:629-654.

61. Madathiparambil MG, Kaleysa KN, Raghavan K. A diagnostically useful 200-kDa protein is secreted through the surface pores of the filarial parasite Setaria digitata. Parasitology Research, 2009, 105:1099-1104. 